\title{
Erratum zu: Heilpflanzen für Nerven, Psyche und Schlaf
}

\section{Erratum zu : A. Riffel, Heilpflanzen für Nerven, Psyche und Schlaf, - https://doi.org/10.1007/978-3-662-60344-4}

Durch ein Versehen während des Herstellungsprozesses wurde der Name der Buchautorin zunächst falsch publiziert.

Dies wurde nun korrigiert.

Die Online-Version des korrigierten Buches finden Sie unter

- https://doi.org/10.1007/978-3-662-60344-4 